\title{
Spatial distribution of similar aftershocks of a large inland earthquake, the 2000 Western Tottori earthquake, in Japan
}

\author{
Misaki Hayashi ${ }^{1}$ and Yoshihiro Hiramatsu ${ }^{2}$ \\ ${ }^{1}$ Graduate School of Natural Science and Technology, Kanazawa University, Kakuma, Kanazawa, Ishikawa 920-1192, Japan \\ ${ }^{2}$ School of Natural System, College of Science and Engineering, Kanazawa University, Kakuma, Kanazawa, Ishikawa 920-1192, Japan
}

(Received May 1, 2013; Revised September 2, 2013; Accepted September 3, 2013; Online published December 6, 2013)

\begin{abstract}
We detected similar aftershocks of the 2000 Western Tottori earthquake and we have examined their spatial distribution on the source fault. Many similar aftershocks are distributed in the northern part of the source fault, but few in the southern part. Specifically, similar aftershocks on the source fault are located outside of the asperity. The cumulative slip estimated from the similar aftershocks is $0.4-2.4 \mathrm{~cm}$. The largest one is found at the edge of the major asperity. We observe that shallower events show a larger cumulative slip than deeper events. Large cumulative slip in the shallow depth in the northern part is coincident with the geodetic observation of afterslip. These facts suggest that similar aftershocks can provide information related to afterslip. However, the slip velocity estimated from both the slip and the recurrence interval of the similar aftershocks shows no distinct distribution.
\end{abstract}

Key words: Similar earthquake, asperity, aseismic slip, afterslip.

\section{Introduction}

Aftershocks following a large earthquake show striking features of a temporal decay rate, Omori's law (Omori, 1894), and spatial distribution. The spatial distribution of aftershocks usually provides information related to the source fault of the preceding large earthquake. The spatial extent of aftershocks is used to estimate the source fault location. Furthermore, the precise location of aftershocks can suggest a rupture pattern on the source fault. For example, in the case of the 2011 off the Pacific coast of Tohoku earthquake, the aftershocks on the plate interface were distributed not in the coseismic slip area but in the surrounding areas (e.g. Asano et al., 2011).

Not only aftershocks but also afterslips follow large earthquakes. Development of a dense geodetic network enables the detection of afterslips. Ozawa et al. (2011) reported that a large afterslip occurred around a large coseismic slip area for the 2011 off the Pacific coast of Tohoku earthquake. A distribution of repeating earthquakes before the 2011 off the Pacific coast of Tohoku earthquake revealed a large afterslip area (Uchida and Matsuzawa, 2011). Recently, Hiramatsu et al. (2011) examined similar aftershocks, which show high cross-correlation coefficients ( $\geq$ 0.95 ) of waveforms at the same station and share an almost identical source area, i.e., almost the same source location and the same focal mechanism, of the 2007 Noto Hanto earthquake. They showed that similar aftershocks on the source fault are located mainly around the deeper edge of the major asperity. This result suggests that the afterslip

Copyright (c) The Society of Geomagnetism and Earth, Planetary and Space Sciences (SGEPSS); The Seismological Society of Japan; The Volcanological Society of Japan; The Geodetic Society of Japan; The Japanese Society for Planetary Sciences; TERRAPUB.

doi:10.5047/eps.2013.09.002 area is spatially complementary to the asperity on the fault surface for inland earthquakes similar to large interplate earthquakes on the plate interface (Hiramatsu et al., 2011). However, to confirm this possibility, we must examine the existence and the spatial distribution of similar aftershocks for other large inland earthquakes.

The 2000 Western Tottori earthquake $\left(M_{\mathrm{W}} 6.6\right)$ occurred on 6 October, 2000, at a depth of $11 \mathrm{~km}$ in southwestern Japan. A detailed aftershock distribution revealed that the source fault consisted of four nearly vertical planes with an NW-SE strike and one plane with an E-W strike (Fukuyama et al., 2001). Based on this configuration of the source fault, a joint inversion of strong motion data and coseismic crustal movement from GPS and leveling data showed that the dominant slip area with a left lateral slip, up to $4 \mathrm{~m}$, was distributed in the southern part of the source fault, especially a shallower part above the hypocenter (Iwata and Sekiguchi, 2002).

The Group for the Dense Aftershock Observations of the 2000 Western Tottori Earthquake conducted a dense aftershock observation from 13 October to early December in 2000 (Group for the Dense Aftershock Observations of the 2000 Western Tottori Earthquake, 2001) (Fig. 1). They installed three-component short-period velocity seismometers at most stations and recorded continuously with a sampling rate of $100 \mathrm{~Hz}$. With this dense network data, a detailed distribution and focal mechanisms of the aftershocks, the three-dimensional velocity structure around the source region, and a regional stress field have been reported (Shibutani et al., 2005; Yukutake et al., 2007).

In this study, we describe a detailed distribution of similar aftershocks of the 2000 Western Tottori earthquake obtained using this dense network data. Furthermore, we examine the relation between the distribution of a similar 


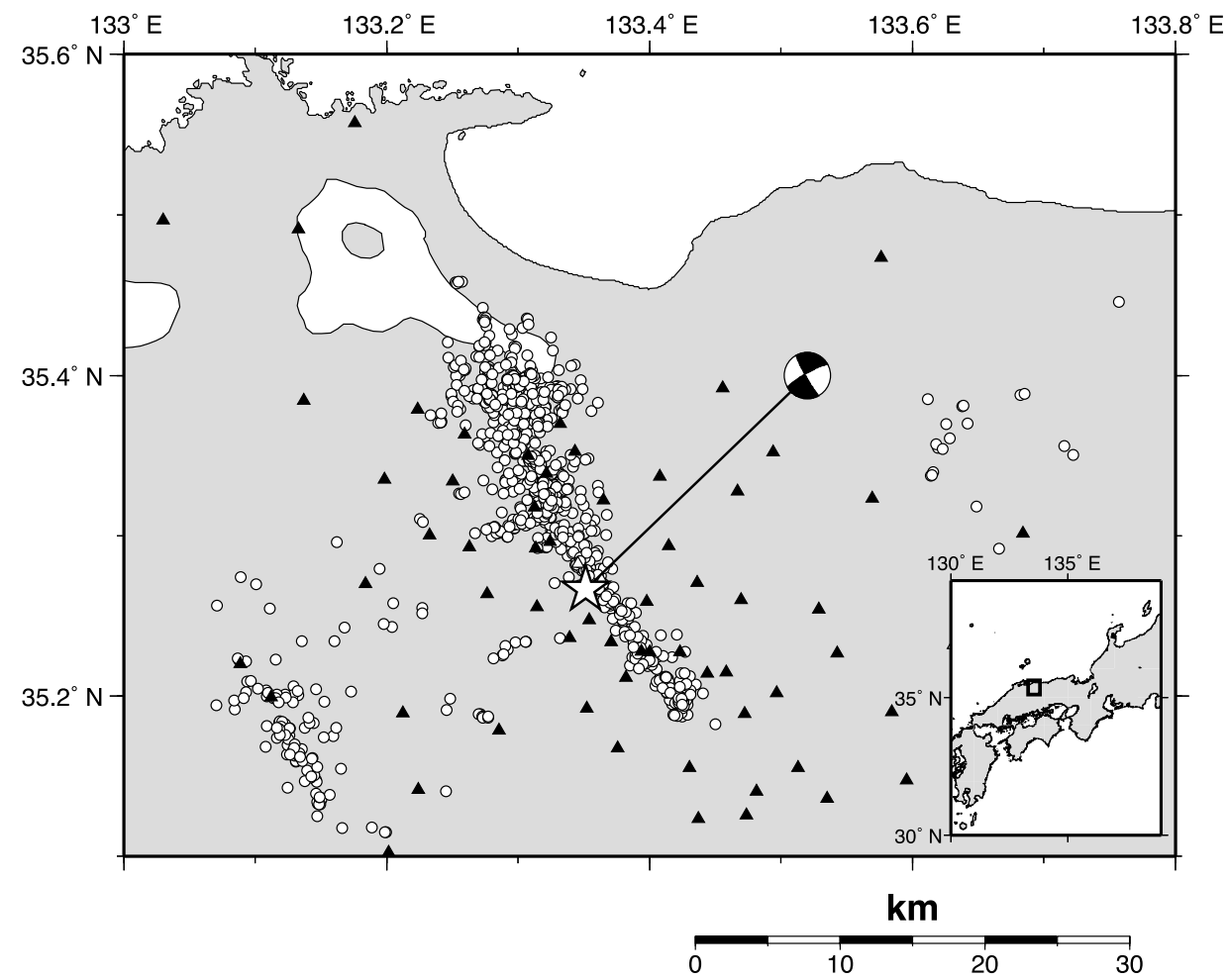

Fig. 1. Distribution of the epicenters of the mainshock (star) and the aftershocks (circles) during 15-25 October in 2000, and the seismic stations (triangles). The focal mechanism of the mainshock is represented by the lower hemisphere projection.

earthquake and the asperity, and report a spatially complementary distribution between them.

\section{Data and Method}

We analyze waveform data, provided by the Group for the Dense Aftershock Observations of the 2000 Western Tottori Earthquake, of 1089 events that occurred during October 15-25 determined by Shibutani et al. (2005) (Fig. 1). The lower limit of those magnitudes is 0.5 . We use $P$-wave and $S$-wave velocity structures and station corrections provided by Shibutani et al. (2005) for the relocation of the hypocenters.

Our procedure to detect similar aftershocks follows that applied by Hiramatsu et al. (2011). First, we select pairs of aftershocks of which the cross-correlation coefficients in a 10 -s time window of $1-4 \mathrm{~Hz}$ band-pass filtered waveforms are greater than 0.95 at more than five stations. We set the start of the time window as $0.3 \mathrm{~s}$ before the $P$ wave arrival. The 10 -s time window includes the $S$-wave arrival. We classify several pairs of aftershocks that are connected by the same event as one group. Linking the cross-correlation coefficients divides these pairs into 111 groups. We reexamine the arrival times of the $P$-waves and $S$-waves and the maximum amplitude of these earthquakes using the WIN system (Urabe and Tsukada, 1991) and determine their hypocenters using hypomh (Hirata and Matsu'ura, 1987). We specifically examine similar aftershocks on the source fault and exclude events far from the fault planes of Iwata and Sekiguchi (2002).

Second, for the events of each group, we calculate the precise travel time differences of $P$-waves and $S$-waves from the cross-spectrum at $1-8 \mathrm{~Hz}$ frequency bands at which the root mean square of the coherency is greater than 0.8 (Ito, 1985). We then relocate the earthquakes of each group using the double-difference method (Waldhauser and Ellsworth, 2000) (Fig. 2).

Third, we estimate the source radius $r$ of an earthquake from the magnitude $M$ using a scaling relation between the scalar moment $M_{\mathrm{o}}(\mathrm{N} \mathrm{m})$ and the magnitude (Hanks and Kanamori, 1979), $\log M_{\mathrm{o}}=1.5 M+9.1$, and the circular fault model of Brune (1970), $\Delta \sigma=7 M_{\mathrm{o}} / 16 r^{3}$. We use here the magnitude determined by Shibutani et al. (2005). Ito (2005) reported that the average static stress drop of the aftershocks of the 2000 Western Tottori earthquake was about $3 \mathrm{MPa}$. We adopt this value as $\Delta \sigma$ in this study.

Figure 2 presents an example of similar aftershock analysis. The band-pass filtered (1-8 Hz) waveforms closely resemble one another, the relocated hypocenters are very close, and the sources share an almost identical area. These facts clearly indicate that these events rupture the same small asperity on the source fault of the 2000 Western Tottori earthquake. However, some groups show a sparse distribution of hypocenters. In this case, we judge that these events are not similar aftershocks. A detailed methodology to judge similar aftershocks for more complicated cases is described in Hiramatsu et al. (2011).

Following the procedure described above, we select 28 groups of similar aftershocks on the source fault of the 2000 Western Tottori earthquake (Fig. 3). Most similar aftershocks are located in the northern part of the source fault, although a few are in the southern part where the large slip was estimated by Iwata and Sekiguchi (2002). Twentytwo groups consist of two events, three groups include three events, and three groups have more than four events. 
(a)

Along Strike

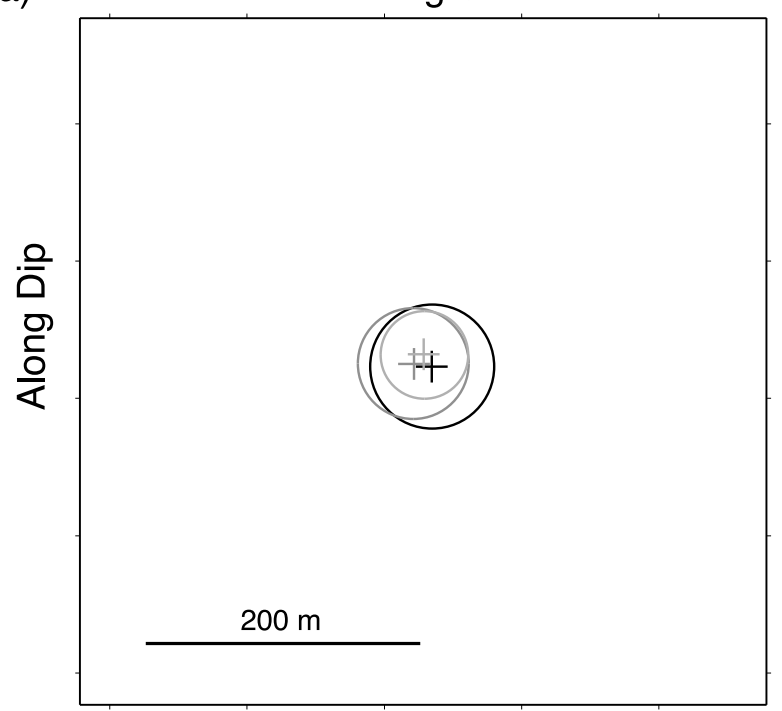

(b)

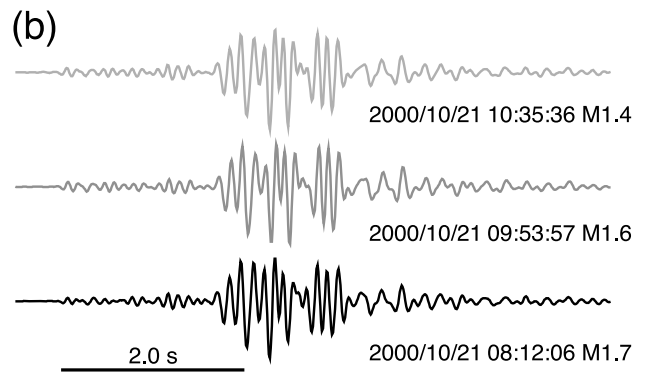

(c) $133.2^{\circ} \mathrm{E} \quad 133.4^{\circ} \mathrm{E}$

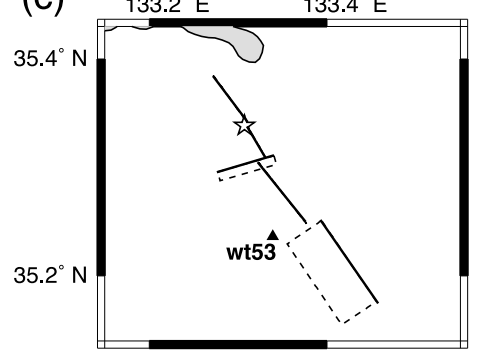

Fig. 2. Example of the analysis of similar aftershocks. (a) Hypocenter distribution of earthquakes reexamined manually and determined using the double-difference method (plusses) projected on the fault plane. The azimuth and the dip of the fault normal are $234^{\circ}$ and $0^{\circ}$, respectively. Circles represent the source radius estimated by the circular crack model with a constant static stress drop of $3 \mathrm{MPa}$. (b) Band-pass filtered (1-8 Hz) waveforms of the vertical component recorded at the wt53 station. The amplitude of each waveform is normalized to unity. The origin time (JST) and the magnitude are displayed at the bottom right of each waveform. (c) Location of the source fault (dotted rectangle with the solid line as the upper edge) (Iwata and Sekiguchi, 2002) and the station wt53. A star shows the average epicenter of these similar aftershocks.

The slip of each event is estimated from extrapolation of the empirical relation, $d=1.56 \times 10^{-7} \times M_{\mathrm{o}}{ }^{1 / 3}$, between the scalar moment $M_{\mathrm{o}}($ dyne.cm) and the slip $d(\mathrm{~cm})$ reported by Somerville et al. (1999). Hiramatsu et al. (2011) pointed out that this relation provided reasonable values for similar aftershocks of the 2007 Noto Hanto earthquake-an inland earthquake - in contrast to the relation reported by Nadeau and Johnson (1998) for repeating earthquakes at a plate boundary, that has been applied to the case of repeating earthquakes in California (Nadeau and McEvilly, 1999), in northeastern Japan (Igarashi et al., 2003; Uchida et al., 2004, 2009; Uchida and Matsuzawa, 2011), in Sumatra (Yu et al., 2013), and in Taiwan (Chen et al., 2008).

\section{Results and Discussion}

Figure 4 presents a spatial distribution of the similar earthquake groups on the source fault of the 2000 Western Tottori earthquake with the slip distribution reported by Iwata and Sekiguchi (2002). No aftershocks occur in the largest slip area beyond $4 \mathrm{~m}$, although some aftershocks are located on the large slip area of 2-4 m. This feature enables us to compare the location of similar aftershocks with that of the asperity (slip is larger than $2 \mathrm{~m}$ ) of the 2000 Western Tottori earthquake, although the comparison might be less pronounced than in the case of the 2007 Noto
Hanto earthquake. We note that similar aftershocks are distributed around or outside the asperity of the main shock (Fig. 4). This feature resembles the distribution of similar aftershocks of the 2007 Noto Hanto earthquake $\left(M_{\mathrm{W}} 6.6\right)$ as reported by Hiramatsu et al. (2011) and the distribution of repeating earthquakes at a plate boundary (Nadeau and McEvilly, 1999; Igarashi et al., 2003; Uchida et al., 2004, 2009; Uchida and Matsuzawa, 2011; Yu et al., 2013).

The cumulative slip of each group ranges from $0.4 \mathrm{~cm}$ to $2.4 \mathrm{~cm}$ (Fig. 4). The cumulative slip is large on average in the northern part of the source fault where the coseismic slip is small. Another interesting feature is the depth variation in the cumulative slip. The cumulative slip tends to be large for shallow groups, although it tends to be small for deep groups. Hiramatsu et al. (2011) reported that the distribution of similar aftershocks on the source fault reflects the area and the amount of afterslip. If this idea is adapted to the case of the 2000 Western Tottori earthquake, then the spatial distribution of the similar aftershocks reported here implies that the afterslip occurred mainly in the northern shallow part on the source fault. Alternatively, the spatial distribution might be controlled by a spatial distribution of small asperities that cause similar aftershocks, as pointed out by Hiramatsu et al. (2011). However, this may not be so in the case of the 2000 Western Tottori earthquake, as 


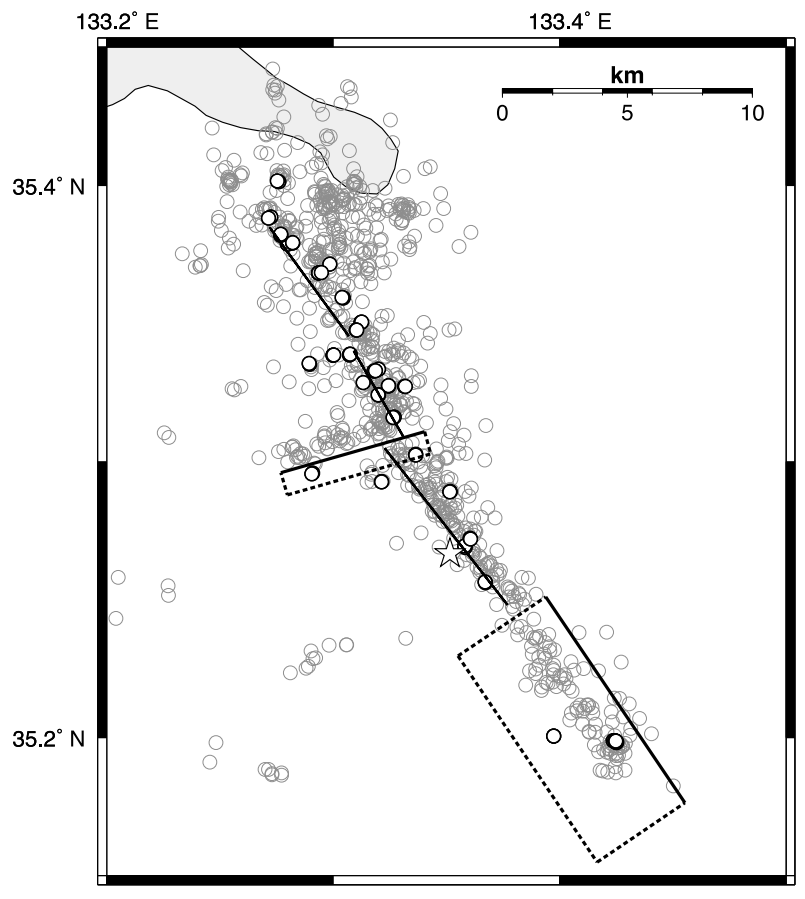

Fig. 3. Distribution of similar aftershocks determined in this study (black circles) and the aftershocks (gray circles), and the location of the source fault (dotted rectangles with the solid line as the upper edge) (Iwata and Sekiguchi, 2002). A star denotes the epicenter of the main shock.

mentioned below.

The postseismic crustal movement was observed using GPS (Sagiya et al., 2002). Relatively large postseismic crustal deformation was recognized at temporal GPS sites deployed around the northern part of the source area. Sagiya et al. (2002) therefore suggested that the afterslip was likely to have occurred mainly in the northern part of the source area. This is coincident with the afterslip distribution inferred from the similar aftershocks. A quantitative comparison of the slip estimated from the similar aftershocks with the afterslip distribution estimated geodetically is more effective to show the consistency. Unfortunately, no report in the relevant literature has estimated the afterslip distribution on the source fault of the 2000 Western Tottori earthquake using the GPS observations.

Sagiya et al. (2002) showed that the observed postseismic deformation is less than $1 \mathrm{~cm}$ during the period analyzed in this study. In this study, we applied the scaling relation of Somerville et al. (1999) to estimate the slip from the similar aftershocks. If we apply the scaling relation of Nadeau and Johnson (1998), the cumulative slip is estimated to be several tens of centimeters. This estimation is obviously too large to reproduce the observed postseismic deformation. On the other hand, the cumulative slip of up to several centimeters, estimated from the scaling relation of Somerville et al. (1999), seems to be adequate for the observed postseismic deformation.

This geodetic observation emphasizes that the source area of similar aftershocks apparently corresponds to the afterslip area, although we cannot present a quantitative comparison because of the lack of geodetic estimation of the afterslip distribution on the source fault. These features suggest that similar aftershocks observed here are possibly caused by a stress accumulation attributable to aseismic slip outside the asperity. We consider, together with the result of the 2007 Noto Hanto earthquake (Hiramatsu et al., 2011), that a spatially complementary distribution between similar aftershocks and asperity is a characteristic of inland earthquakes.

Figure 4(b) shows the distribution of the slip velocity that was estimated from both the time interval between the successive two earthquakes of each group and the slip of the later event. We use the average slip velocity for groups with more than three similar aftershocks. It is difficult to find a distinct pattern of the spatial distribution of the slip velocity along strike or along dip. For the 2007 Noto Hanto earthquake, the slip velocity tends to be large at the edge of the asperity (Hiramatsu et al., 2011). However, we cannot recognize such a feature for the 2000 Western Tottori earthquake.

The recurrence interval, $T_{\mathrm{r}}$, of similar aftershocks of interplate earthquakes shows a distinct power-law temporal feature as $T_{\mathrm{r}} \sim t^{p}$, where $t$ is the elapsed time from the mainshock and $p$ is a constant: the values of $p$ are less than 1 (Peng et al., 2005) and 0.8-1.1 (Yu et al., 2013). Some groups of similar aftershocks of the 2000 Western Tottori earthquake seem to show a longer interval as the elapsed time increases, showing consistency with the previous works. However, the number of events in a group are too small to examine the power-law temporal feature. More events with a longer analyzed period are needed in order to examine this.

There are many studies on repeating earthquakes on plate interfaces that apply the empirical scaling relation of $d \propto$ $M_{\mathrm{o}}^{1 / 6}$ between the slip, $d$, and the seismic moment, $M_{\mathrm{o}}$, of Nadeau and Johnson (1998) to monitor spatio-temporal variation in aseismic slip and/or aseismic slip rate at a plate boundary (Nadeau and McEvilly, 1999; Igarashi et al., 2003; Uchida et al., 2004, 2009; Chen et al., 2008; Uchida and Matsuzawa, 2011, Yu et al., 2013).

Those studies seem to support the scaling relation of Nadeau and Johnson (1998). However, the results of this study and Hiramatsu et al. (2011) argue that the scaling relation of Nadeau and Johnson (1998) is inadequate to estimate slip for inland earthquakes. The difference of the scaling relation between Nadeau and Johnson (1998) and Somerville et al. (1999) is possibly attributed to a static stress drop, $\Delta \sigma$. The scaling relation of Somerville et al. (1999) maintains a constant static stress drop. On the other hand, Nadeau and Johnson (1998) proposed an additional scaling relation between $\Delta \sigma$ and $M_{\mathrm{o}}$, viz., $\Delta \sigma \propto M_{\mathrm{o}}^{-1 / 4}$. This scaling relation departs from a constant static stress drop, which is accepted widely in seismology. The seismic moment dependency of $\Delta \sigma$ has not been confirmed by recent studies. For example, Imanishi and Ellsworth (2006) analyzed waveforms of microearthquakes recorded at SAFOD Pilot Hole at Parkfield and obtained momentindependent scaling of the static stress drop. More recently, Yoshimitsu (2012) reported that repeating acoustic emission events showed a constant static stress drop based on laboratory experiments. The previous works of repeating earthquakes on a plate boundary do not confirm a seismic 
(a)

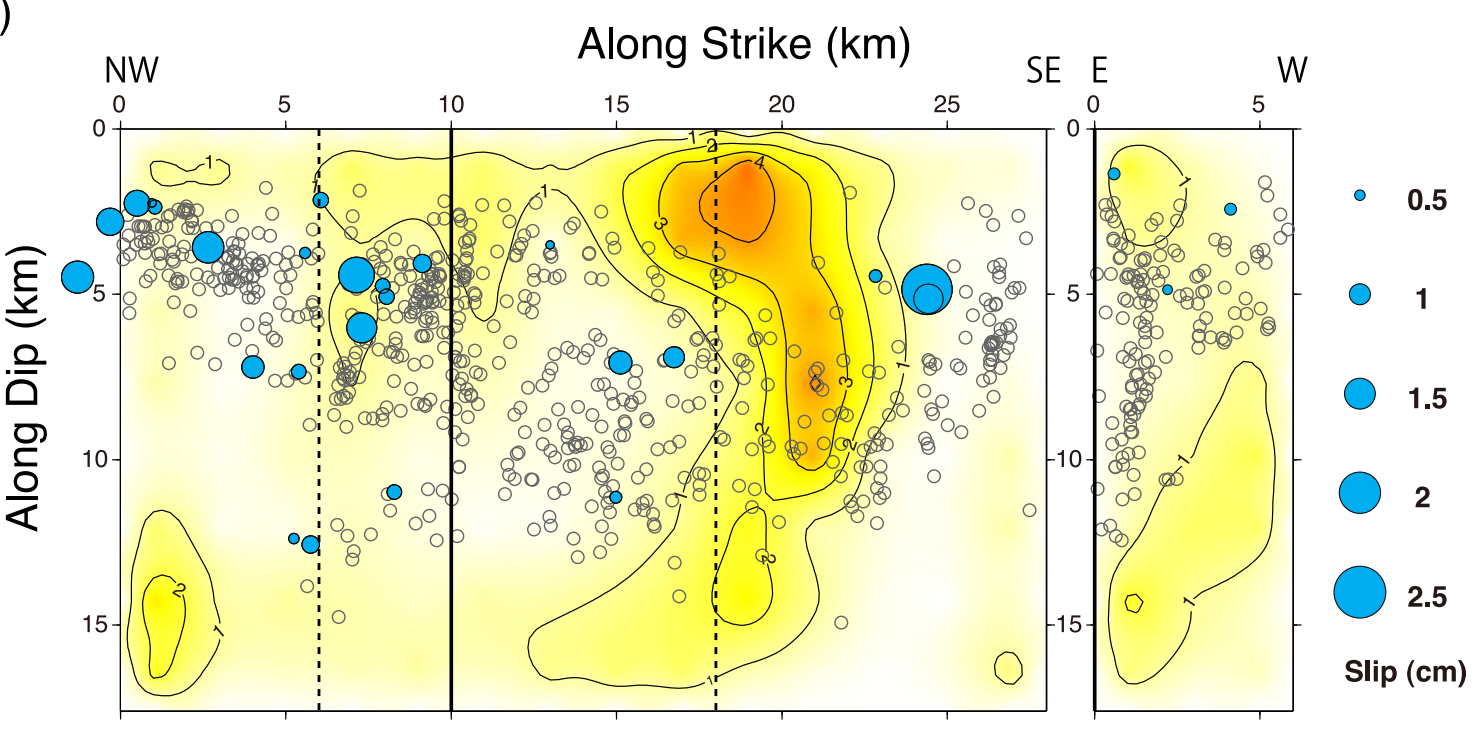

(b)

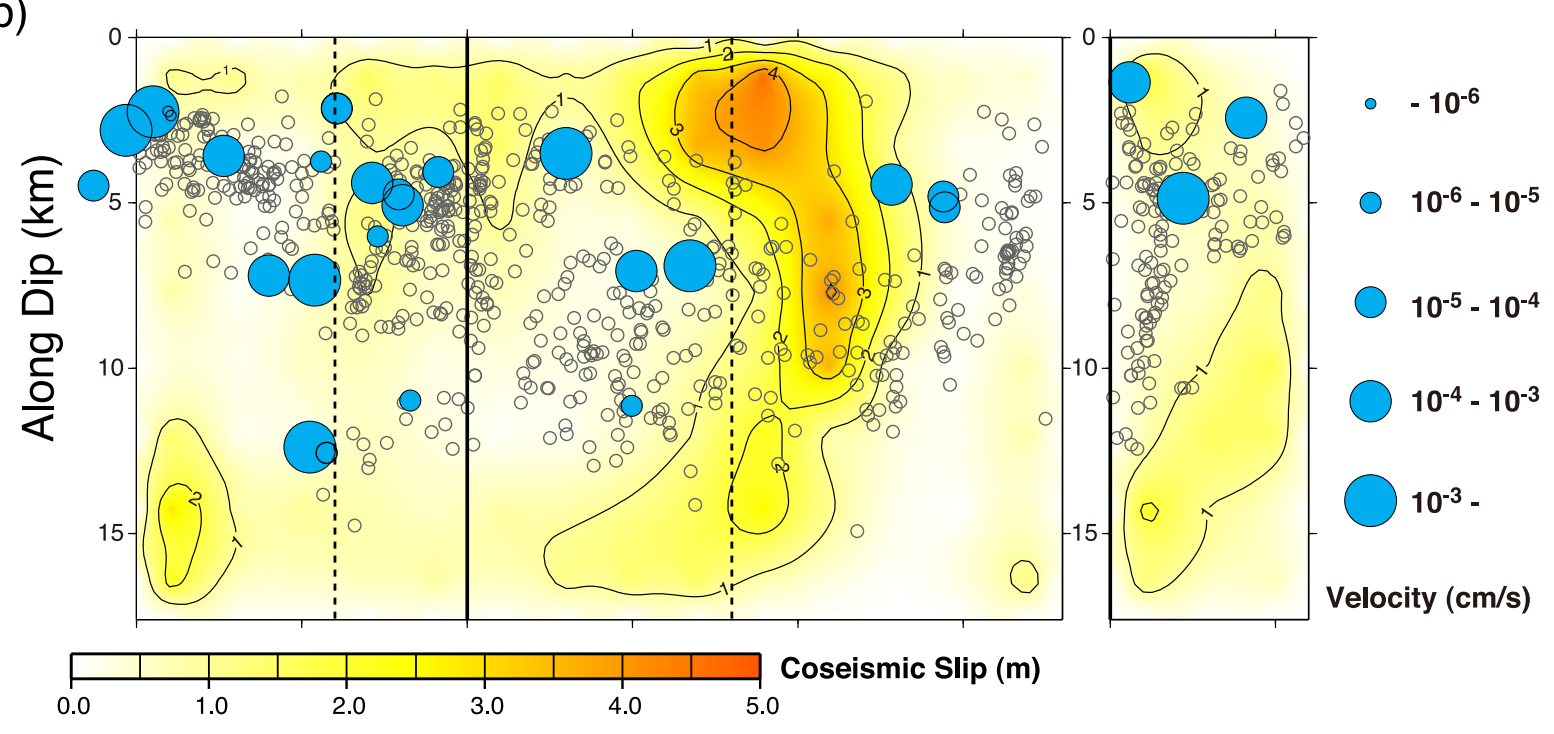

Fig. 4. (a) Distribution of cumulative slip, and (b) the distribution of the slip velocity estimated from similar aftershocks (solid circles) projected on the fault plane. Left panels represent the sub-faults trending NW-SE and right panels the sub-fault trending E-W reported by Iwata and Sekiguchi (2002). The aftershocks are represented by open circles. The contour lines (1-m contour interval) and a color scale represent the coseismic slip estimated by Iwata and Sekiguchi (2002). Dashed lines in left panels are the boundary of the sub-faults. Solid lines in the both panels represent the line of intersection of the sub-fault trending NW-SE and that trending E-W.

moment dependency of the static stress drop although they applied the scaling relation of Nadeau and Johnson (1998).

The scaling relation of $\Delta \sigma \propto M_{\mathrm{o}}^{-1 / 4}$ is derived based on the assumption of $100 \%$ seismic coupling (Nadeau and Johnson, 1998). If a constant static stress drop is valid for repeating earthquakes on the plate interface, the seismic coupling would be smaller. If this is the case, the difference in the scaling relation to estimate aseismic slip between interplate earthquakes and inland earthquakes may be interpreted by a difference of the seismic coupling between small asperities and the surrounding aseismic slip.

\section{Conclusions}

We have investigated the spatial relation between similar aftershocks and the asperity of the 2000 Western Tottori earthquake from analysis of dense temporary seismic observation data. Many similar aftershocks are distributed in the northern part of the source fault, but few in the southern part. We find no similar aftershocks in the asperity, i.e., the asperity and the similar aftershocks show a spatially complementary distribution. The cumulative slip of the similar aftershocks, estimated from empirical scaling relations, is large in the shallow depth in the northern part. This is coincident with the geodetic observation that provided large postseismic crustal deformation around the northern area of the source fault. In other words, the similar aftershocks are phenomena that relate to afterslip. We also estimate the slip velocity from both the slip and the recurrence interval of the similar aftershocks. However, the slip velocity shows no distinct distribution.

Acknowledgments. We thank the Group for the Dense Aftershock Observations of the 2000 Western Tottori Earthquake, Earthquake Research Institute, the University of Tokyo, Disaster Prevention Research Institute, Kyoto University, Japan Meteoro- 
logical Agency, and National Research Institute for Earth Science and Disaster Prevention for providing waveform data of the aftershocks of the 2000 Western Tottori earthquake. We are grateful to Tomotaka Iwata and Haruko Sekiguchi for providing their result. Comments from anonymous reviewers and Tatsuhiko Hara helped to improve the manuscript. All figures are drawn using GMT software (Wessel and Smith, 1998).

\section{References}

Asano, Y., T. Saito, Y. Ito, K. Shiomi, H. Hirose, T. Matsumoto, S. Aoi, S. Hori, and S. Sekiguchi, Spatial distribution and focal mechanisms of aftershocks of the 2011 off the Pacific coast of Tohoku Earthquake, Earth Planets Space, 63, 669-673, 2011.

Brune, J. N., Tectonic stress and the spectra of seismic shear waves from earthquakes, J. Geophys. Res., 75, 4997-5009, 1970.

Chen, K. H., R. M. Nadeau, and R. J. Rau, Characteristic repeating earthquakes in an arc-continent collision boundary zone: The Chihshang fault of eastern Taiwan, Earth Planet. Sci. Lett., 276, 262272, doi:10.1016/j.epsl.2008.09.021, 2008.

Fukuyama, E., W. L. Ellsworth, F. Waldhauser, and A. Kubo, Very fine fault structure of the 2000 Western Tottori, Japan, Earthquake, paper presented at 2001 Joint Meeting for Earth and Planetary Science, Tokyo, Japan, 4 June, 2001.

Group for the Dense Aftershock Observations of the 2000 Western Tottori Earthquake, Distribution and focal mechanisms of aftershocks of the 2000 Western Tottori Earthquake revealed by dense aftershock observation, News Lett. Seismol. Soc. Jpn., 13, 23-27, 2001 (in Japanese).

Hanks, T. C. and H. Kanamori, A moment magnitude scale, J. Geophys. Res., 84, 2348-2350, 1979.

Hiramatsu, Y., M. Hayashi, A. Hayashi, and the Group for the Joint Aftershock Observations of the 2007 Noto Hanto Earthquake, Relation between similar aftershocks and ruptured asperity of a large inland earthquake: Example of the 2007 Noto Hanto earthquake, Earth Planets Space, 63, 145-149, 2011

Hirata, N. and M. Matsu'ura, Maximum-likelihood estimation of hypocenter with origin time eliminated using nonlinear inversion technique, Phys. Earth Planet. Inter., 47, 50-61, 1987.

Igarashi, T., T. Matsuzawa, and A. Hasegawa, Repeating earthquakes and interplate aseismic slip in the northeastern Japan subduction zone, $J$. Geophys. Res., 108, doi:10.1029/2002JB001920, 2003.

Imanishi, K. and W. L. Ellsworth, Source scaling relationships of microearthquakes at Parkfield, CA, determined using the SAFOD pilot hole seismic array, in Earthquakes: Radiated Energy and the Physics of Earthquake Faulting, edited by R. E. Abercrombie, A. McGarr, H. Kanamori and G. Di Toro, Geophys. Monogr. Ser., 170, 81-90, AGU, Washington, D. C., doi:10.1029/GM170, 2006.

Ito, A., High resolution relative hypocenters of similar earthquakes by cross-spectral analysis method, J. Phys. Earth, 33, 279-294, 1985.

Ito, Y., Mechanisms of aftershock generation, Report of the National Research Institute for Earth Science and Disaster Prevention, 68, 27-89, 2005 (in Japanese with English abstract).

Iwata, T. and H. Sekiguchi, Source inversion of recent earthquakes using strong motion records, in a special issue on Strong Motion Prediction, Chikyu Monthly, 37, 47-55, 2002 (in Japanese).

Nadeau, R. M. and L. R. Johnson, Seismological studies at Parkfield VI: Moment release rates and estimates of source parameters for small repeating earthquakes, Bull. Seismol. Soc. Am., 88, 790-814, 1998.
Nadeau, R. M. and T. V. McEvilly, Fault slip rates at depth from recurrence intervals of repeating microearthquakes, Science, 285, 718-721, 1999.

Omori, F., On aftershocks, Rep. Imp. Earthq. Investig. Comm., 2, 103-139, 1894 (in Japanese).

Ozawa, S., T. Nishimura, H. Suito, T. Kobayashi, M. Tobita, and T. Imakiire, Coseismic and postseismic slip of the 2011 magnitude- 9 TohokuOki earthquake, Nature, doi:10.1038/nature10227, 2011.

Peng, Z., J. E. Vidale, C. Marone, and A. Rubin, Systematic variations in recurrence interval and moment of repeating aftershocks, Geophys. Res. Lett., 32, L15301, doi:10.1029/2005GL022626, 2005.

Sagiya, T., T. Nishimura, Y. Hatanaka, E. Fukuyama, and W. L. Ellsworth, Crustal movements associated with the 2000 Western Tottori Earthquake and its fault models, J. Seismol. Soc. Jpn., 54, 523-534, 2002 (in Japanese with English abstract).

Shibutani, T., H. Katao, and Group for the dense aftershock observations of the 2000 Western Tottori Earthquake, High resolution 3-D velocity structure in the source region of the 2000 Western Tottori Earthquake in southwestern Honshu, Japan using very dense aftershock observations, Earth Planets Space, 57, 825-838, 2005.

Somerville, P. G., K. Irikura, R. Graves, S. Sawada, D. Wald, N. Abrahamson, Y. Iwasaki, T. Kagawa, N. Smith, and A. Kowada, Characterizing crustal earthquake slip models for the prediction of strong ground motion, Seismol. Res. Lett., 70, 59-80, 1999.

Uchida, N. and T. Matsuzawa, Coupling coefficient, hierarchical structure, and earthquake cycle for the source area of the 2011 off the Pacific coast of Tohoku earthquake inferred from small repeating earthquake data, Earth Planets Space, 63, 675-679, 2011.

Uchida, N., A. Hasegawa, T. Matsuzawa, and T. Igarashi, Pre-and post-seismic slow slip on the plate boundary off Sanriku, NE Japan associated with three interplate earthquakes as estimated from small repeating earthquake data, Tectonophysics, 385, 1-15, doi:10.1016/j.tecto.2004.04.015, 2004

Uchida, N., S. Yui, S. Miura, T. Matsuzawa, A. Hasegawa, Y. Motoya, and M. Kasahara, Quasi-static slip on the plate boundary associated with the 2003 M8.0 Tokachi-oki and 2004 M7.1 off-Kushiro earthquakes, Japan, Gondwana Res., 16, 527-533, doi:10.1016/j.gr.2009.04.002, 2009.

Urabe, T. and S. Tsukada, A workstation-assisted processing system for waveform data from microearthquake networks, Abstracts of Spring Meeting of Seismological Society of Japan, 70, 1991 (in Japanese).

Waldhauser, F. and W. L. Ellsworth, A double-difference earthquake location algorithm: Method and application to the northern Hayward fault, California, Bull. Seismol. Soc. Am., 90, 1353-1368, 2000.

Wessel, P. and W. H. F. Smith, New, improved version of Generic Mapping Tools released, Eos Trans. AGU, 79, 579, 1998.

Yoshimitsu, N., The study on applicability of the rock fracture experiments to seismology, PhD thesis, 131 pp., Ritsumeikan University, 2012.

Yu, W., T. R. A. Song, and P. G. Silver, Repeating aftershocks of the great 2004 Sumatra and 2005 Nias earthquakes, J. Asian Earth Sci., 67-68, 153-170, doi:10.1016/j.jseaes.2013.02.018, 2013.

Yukutake, Y., Y. Iio, H. Katao, and T. Shibutani, Estimation of the stress field in the region of the 2000 Western Tottori Earthquake: Using numerous aftershock focal mechanisms, J. Geophys. Res., 112, B09306, doi:10.1029/2005JB004250, 2007.

M. Hayashi and Y. Hiramatsu (e-mail: yoshizo@hakusan.s.kanazawau.ac.jp) 